\title{
The Research and Realization of the Science Feed Management System in Islamic Livestock Norm Production and Quality Attestation System
}

\author{
Rong Ren* and Wenxing Bao \\ The Computer Science and Engineering Institute of North University for Nationalities, \\ YinChuan NingXia, P.R. China 750021 \\ xfrr990@yahoo.com.cn
}

\begin{abstract}
For the request of rational and scientific farming of dairy cow, the database of dairy cow's feed composition and ratio is established, and the feed formula service management platform and transaction processing platform is realized in Science Feed Management System. The application of this system contributes to improve science of dairy cow's feed formula, enhance the utilization of the raw material, attain the target to economize cost and increase benefit. In this system, the web service management platform is developed by SQL SERVER 2005 and JSP technology, and the transaction processing platform is developed by ACCESS and VB6.0.
\end{abstract}

Keywords: feed management system, feed formula, isomerous data.

\section{Introduction}

For the rationalization and scientific requirements of feed formula of dairy cow and other characteristics animal, feed consumption, feed composition and economic efficiency analysis of correlation models is established, information management for animal feed and feed formula customization function modules is developed in Science Feed Management Information System.

Compared with the traditional method, the advantage of this system is not only provide the function of feed formulation management by user, but also can download the expert formulation to use and modify from server.

\section{The System Development Process}

The system's key issue is the establishment and collection of information of the composition and ratio of feed raw materials database.

\footnotetext{
* Corresponding author.
} 
The Development Process of this system is shown in Figure 1:

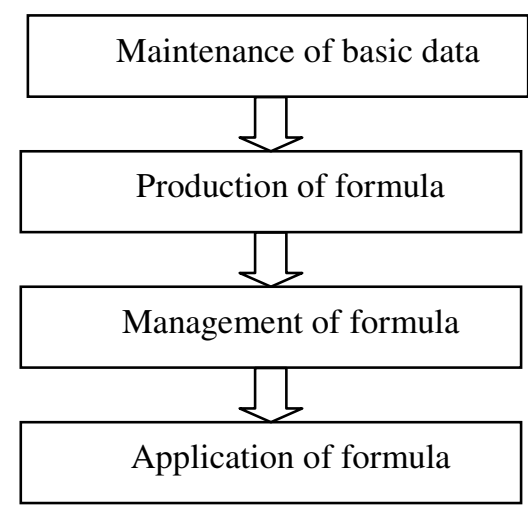

Fig. 1. Development Process

(1) Maintenance of basic data: Manage and Maintain nutrition information, materials information and raising standards information.

(2) Production of formula: produce formula information.

(3) Management of formula: insert information, update information and delete information.

(4) Application of formula: apply results, verify results and improve results.

\section{The Design of System Structure}

The users of "Science Feed Management Information System" are Farms, feed processing factory, etc. This system provides the management function of feed formula and informatization support for these users. The system include tow management platform: service management platform and transaction processing platform.

System structure is shown in Figure 2:

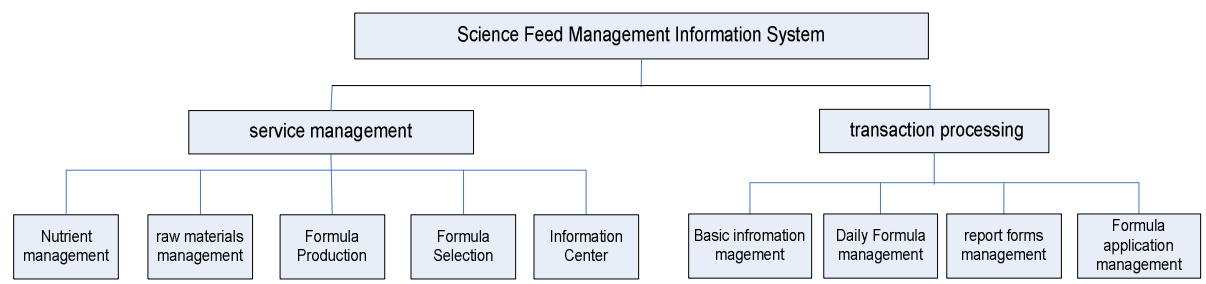

Fig. 2. System Structure 


\section{The Integration Design of Multisource and Isomerous Data}

The integration design of Multisource and isomerous data is shown in Figure 3:
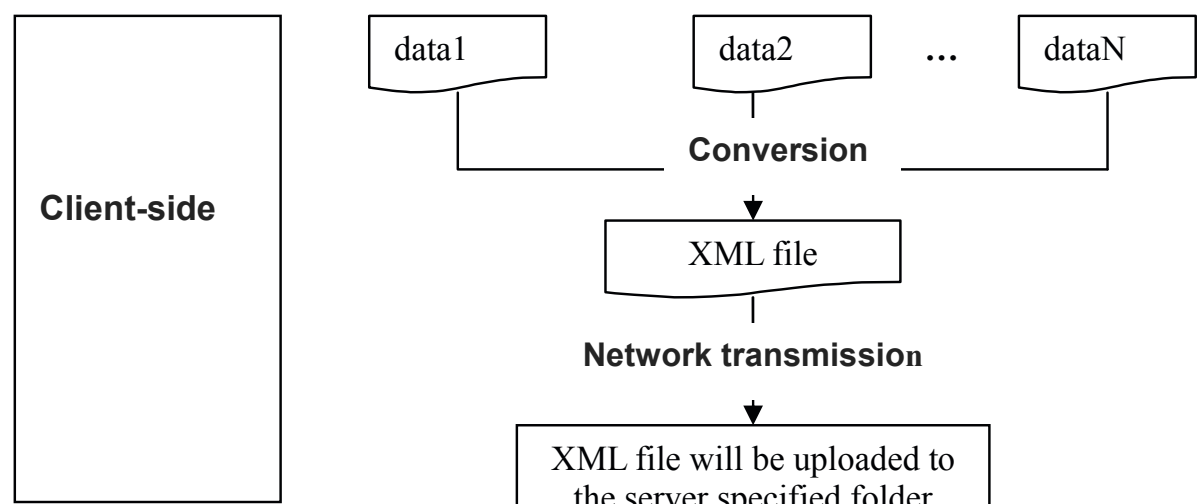

Network transmission

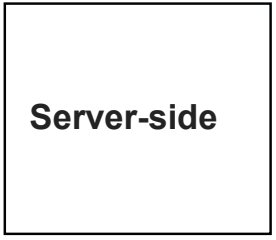

XML file will be uploaded to the server specified folder Import data and data Process

XML file will be imported to the server specified table

Fig. 3. Integration design of Multisource and isomerous data

\section{System Data Module}

The System Data Module is shown in Figure 4: 


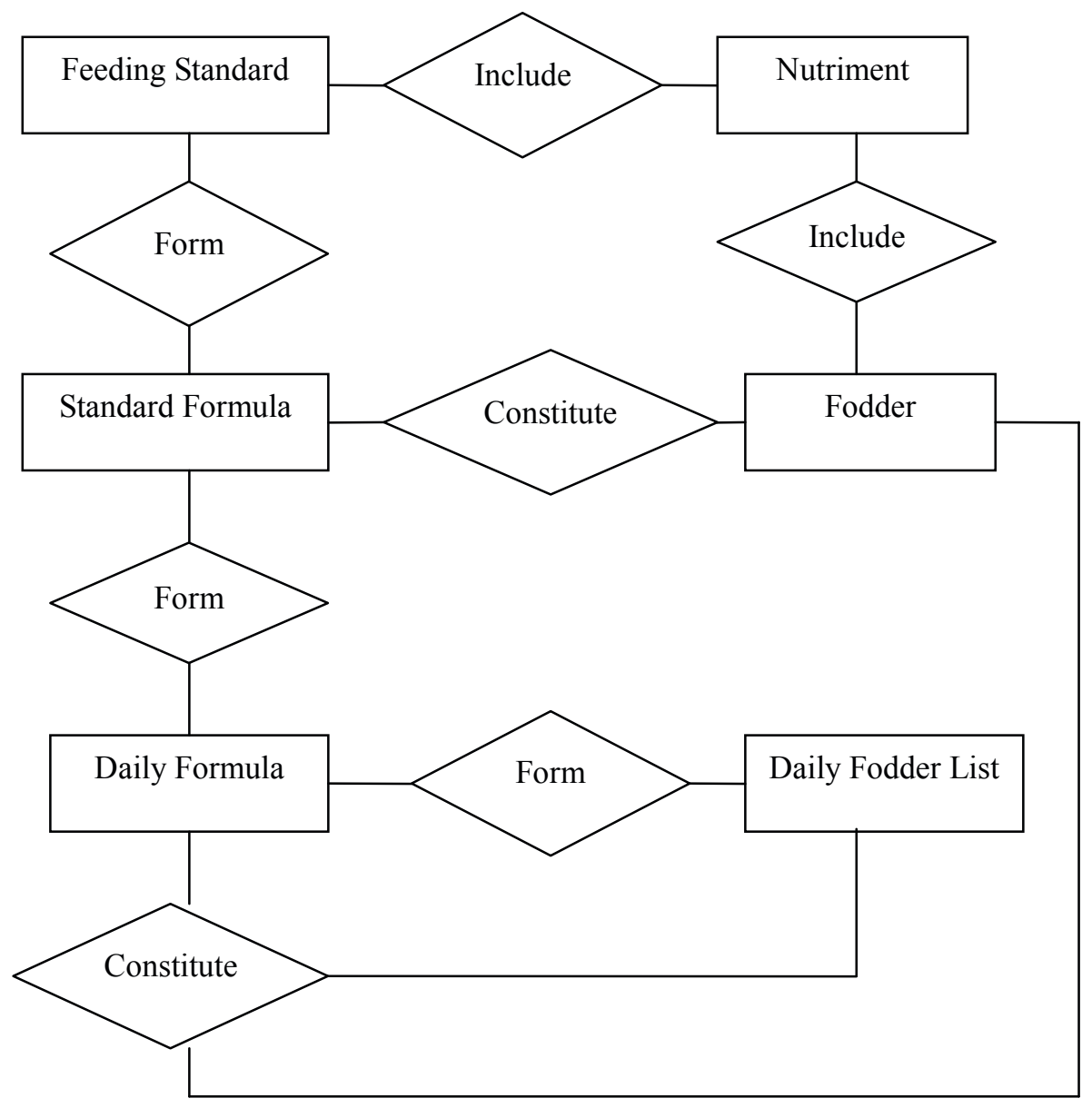

Fig. 4. System Data Module

\section{System Realization}

The web service management platform of Science Feed Management Information System is developed by SQL SERVER 2005 and JSP technology. Transaction processing platform is developed by ACCESS and VB6.0.

The realization of web service management platform is shown in Figure 5: 


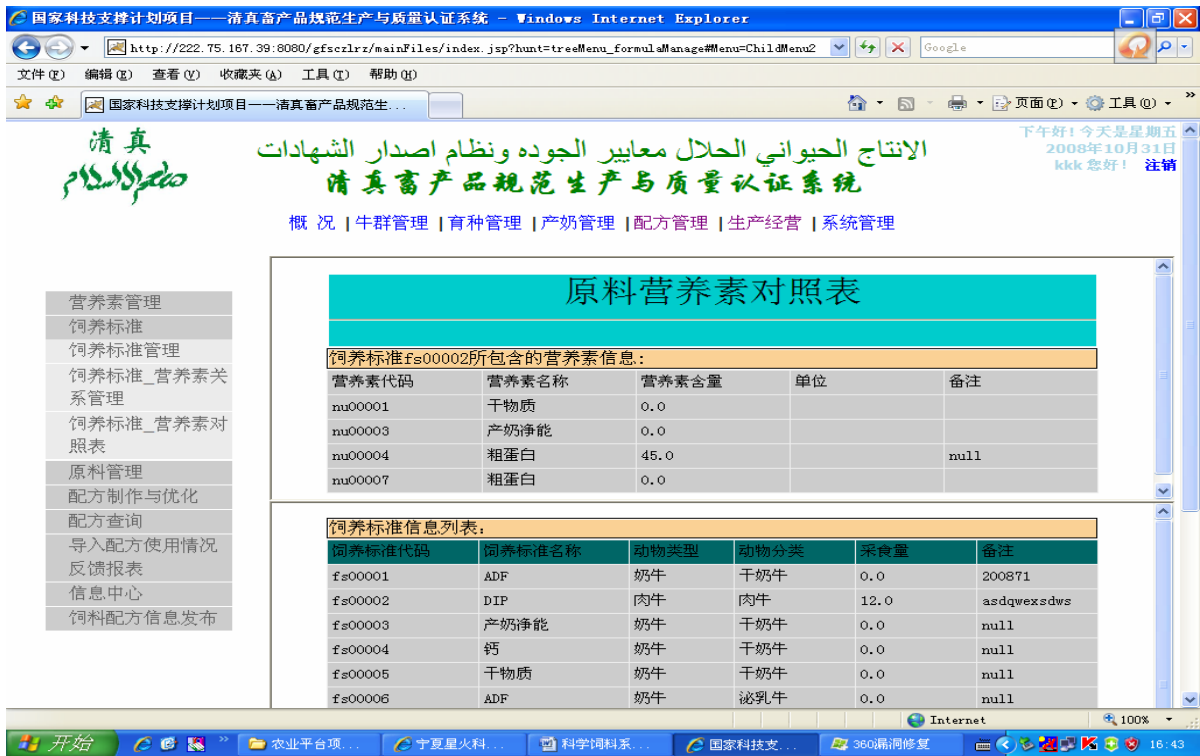

Fig. 5. Realization of web service management platform

The realization of transaction processing platform is shown in Figure 6:

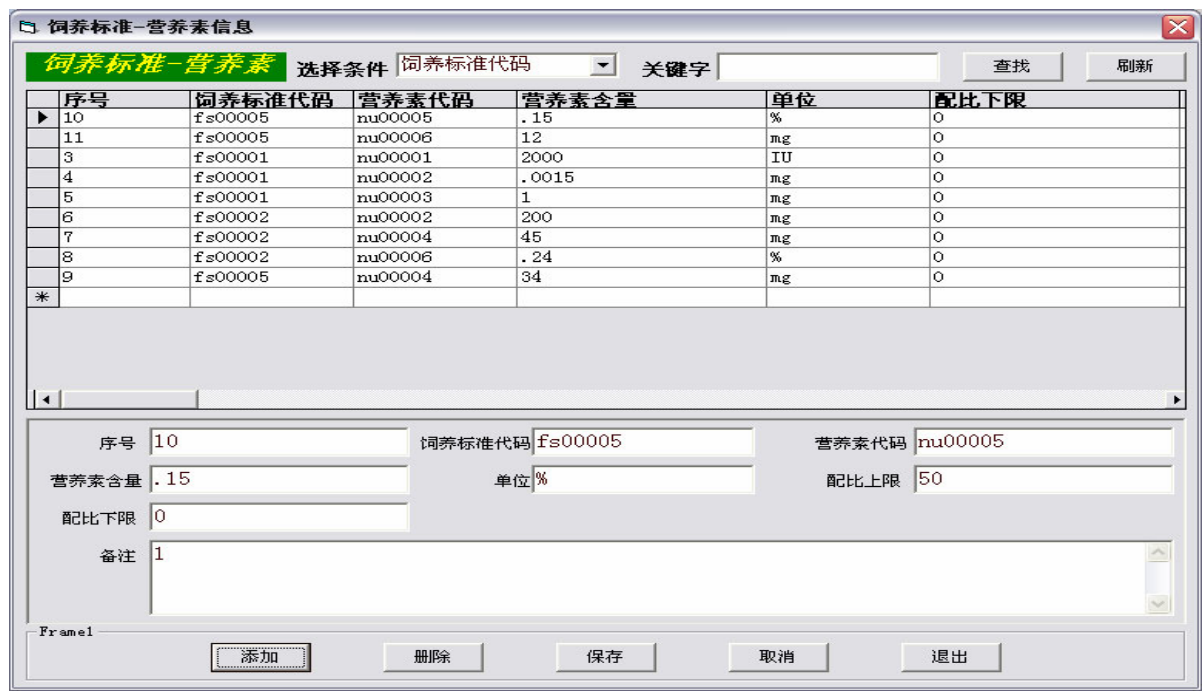

Fig. 6. Realization of transaction processing platform 


\section{Conclusion}

The application of Science Feed Management System can open widely the outlet that the farm obtains the animal feed market data and the formulation information; and have the great significance to lowering the business enterprise farming cost and raising market competition ability.

\section{References}

[1] Li, Z.: Science Compounding and Application of Dairy Cow Feed. Jindun Publisher, BeiJin (2007)

[2] Hong, G.: Healthy Feed Technology of Dairy Cow. Sanxia Publisher in china, BeiJin (2008)

[3] Huisheng, W.: New Technology of Efficient Feed of Dairy Cow. Science Technology Literature Publisher, BeiJin (2006)

[4] Ian, S.: Software Engineering. Machinery Industry Publisher, BeiJin (2007) 